\title{
ARTIKELEN
}

\section{Meer en zwaarder toezicht na detentie}

\section{Uitbreiding van de lijst van bijzondere voorwaarden binnen de voorwaardelijke invrijheidstelling*}

Mirte Bikker**

\section{Inleiding}

De Wet straffen en beschermen, die op 1 juli 2021 in werking treedt, heeft al het nodige stof doen opwaaien. ${ }^{1}$ Op zich is dat niet verwonderlijk. De wet bevat fundamentele wijzigingen van het stelsel van de voorwaardelijke invrijheidstelling (v.i.) van veroordeelden, waarbij het verlenen van v.i. niet langer vanzelfsprekend is en meer nadruk wordt gelegd op de inzet en eigen verantwoordelijkheid van de gedetineerde voor zijn gedrag. ${ }^{2}$ Bovendien is de periode waarin de veroordeelde voorwaardelijk in vrijheid kan worden gesteld, vastgelegd op maximaal twee jaar bij gevangenisstraffen van zes jaar of meer. ${ }^{3}$ Een minder in het oog springend, en later aan het Wetsvoorstel straffen en beschermen toegevoegd onderdeel van de nieuwe v.i.-regeling is een aanzienlijke uitbreiding van de bijzondere voorwaarden die aan de voorwaardelijke invrijheidstelling van een veroordeelde kunnen worden verbonden. Het pakket aan al bestaande bijzondere voorwaarden wordt aangevuld met een woonverbod, een reisverbod, een verbod om vrijwilligerswerk van bepaalde aard te verrichten, een verhuisplicht en de verplichting de door het strafbare feit veroorzaakte schade (gedeeltelijk) te vergoeden. ${ }^{4}$ Deze laatstgenoemde betalingsverplichting is al bekend als een van de mogelijke voorwaarden bij de voorwaardelijke veroordeling. Ook de andere nieuwe bijzondere voorwaarden zijn binnen het strafrechtelijk sanctiearsenaal geen nieuwkomers. De strafrechter kan diezelfde voorwaarden opleggen in het kader van de in 2018 geïntroduceerde gedragsbeïnvloedende en vrijheidsbeperkende maatregel (GVM). Deze maatregel en de daaraan verbonden voorwaarden zijn in het leven geroepen voor ter beschikking gestelden en zware gewelds- en zedendelinquenten. Volgens de toelichting op het later toegevoegde onderdeel van de nieuwe v.i.-regeling is het van belang dat de lijst van 'v.i.-voorwaarden' in lijn wordt gebracht met de lijst zoals die op dit moment in de

* Deze bijdrage is geschreven op persoonlijke titel.

** Mr. Mirte Bikker is masterstudent Jeugdrecht aan de Universiteit Leiden en heeft een afgeronde master Straf- en strafprocesrecht aan diezelfde universiteit (2019). Daarnaast is zij commissiesecretaris bij de Afdeling rechtspraak van de Raad voor Strafrechtstoepassing en Jeugdbescherming. Wet van 24 juni 2020, Stb. 2020, 224; Kamerstukken II 2020/21, 35122, nr. 39.

2 Kamerstukken II 2018/19, 35122, nr. 3, p. 26.

3 Zie hierover P.M. Schuyt, 'Voorwaardelijke invrijheidstelling: het beeld en de werkelijkheid', Sancties 2019, 2, p. 5-13.

$4 \quad$ Kamerstukken II 2018/19, 35122, nr. 7. 
wettelijke regeling van de GVM is opgenomen. ${ }^{5}$ Het gevolg hiervan is dat de ingrijpende 'GVM-voorwaarden' - oorspronkelijk bedoeld voor zware delinquenten openstaan voor iedere gedetineerde die onder voorwaarden in vrijheid wordt gesteld. Binnen het kader van de v.i. kunnen zodoende ernstige inbreuken worden gemaakt op verschillende grondrechten van de veroordeelde.

De voor het huidige tijdsgewricht kenmerkende wens om de positie van slachtoffers - ook gedurende het sluitstuk van de executiefase - te versterken en de maatschappij te beschermen tegen veroordeelden die (mogelijk) een veiligheidsrisico vormen, lijkt de primaire aanleiding te zijn van de uitbreiding van de lijst van bijzondere voorwaarden binnen de v.i. ${ }^{6}$ Dit onderdeel van de nieuwe v.i.-regeling heeft een ingrijpender uitwerking dan wellicht in eerste instantie zou worden bedacht. Eerder is vooral veel aandacht uitgegaan naar de gemaximeerde duur van de v.i. en de aanspraak die gedetineerden op voorwaardelijke invrijheidstelling kunnen maken in relatie tot het belang van resocialisatie, terwijl de concrete invulling van de v.i. in de vorm van het stellen van voorwaarden onderbelicht is gebleven. Aangezien in ongeveer $70 \%$ van de gevallen van voorwaardelijke invrijheidstelling bijzondere voorwaarden worden gesteld, ${ }^{7}$ is het de moeite waard deze wetswijziging nader te bestuderen. In deze bijdrage wordt daarom nagegaan welke juridische implicaties de uitbreiding van de bijzondere voorwaarden heeft ten aanzien van drie thema's: de doelstelling en betekenis van de v.i., de rechtsbescherming van de veroordeelde en de verhouding van de v.i. ten opzichte van de GVM.

In aanloop naar de beantwoording van deze vraag begin ik met een korte bespreking van twee onderdelen van de Wet langdurig toezicht, namelijk de zelfstandige GVM en de mogelijkheid om de proeftijd van de v.i. te verlengen. Daarna komen de wettelijke regeling en de doelstellingen van de v.i. aan bod, evenals de nieuwe, aangevulde opsommingslijst van bijzondere voorwaarden. Vervolgens wordt ingegaan op de implicaties van deze uitbreiding ten aanzien van het eigen karakter van de v.i., de rechtswaarborgen rondom de beslissing om bijzondere voorwaarden te stellen en de (nieuwe) verhouding tussen de v.i. en de GVM. In de slotparagraaf volgen enkele concluderende opmerkingen.

\section{De GVM en de duur van de proeftijd}

Met de (volledige) inwerkingtreding van de Wet langdurig toezicht, gedragsbeïnvloeding en vrijheidsbeperking in 2018 zijn voor zware gewelds- en zedendelinquenten twee wettelijke toezichtkaders in het leven geroepen. ${ }^{8}$ Een daarvan betreft een nieuwe zelfstandige vrijheidsbeperkende maatregel. De GVM (art. 38z Wetboek van Strafrecht (Sr)) biedt een langdurig en zelfstandig toezichtkader

5 Idem, p. 4.

6 Ministerie van JenV, Samen werken aan Recht en Veiligheid, Den Haag 2017, p. 39-42; S. Struijk \& G. Meynen, 'Betrokkenheid van slachtoffers en nabestaanden: ook bij de tenuitvoerlegging', Sancties 2021, 1.

7 J. uit Beijerse e.a., De praktijk van de voorwaardelijke invrijheidstelling in relatie tot speciale preventie en re-integratie, Den Haag: Boom juridisch 2018, p. 70, 152.

8 Stb. 2015, 460. 
waaraan voorwaarden zijn verbonden, specifiek bedoeld voor zowel tbs-gestelden als zware gewelds- en zedendelinquenten. Bij deze laatste categorie veroordeelden vindt het toezicht plaats in aansluiting op de gevangenisstraf of de proeftijd van de v.i. De wetgever, zo volgt uit de wetsgeschiedenis, acht het in het belang van de veiligheid van de maatschappij noodzakelijk dat deze personen, die een zeer ernstig delict hebben gepleegd en bij wie sprake is van een hoog recidiverisico, langdurig of zelfs levenslang onder toezicht kunnen komen te staan. ${ }^{9}$ Aan de hand van een zogeheten tweetrapsprocedure beslist de rechter - na eerder al tot oplegging van de GVM te zijn overgegaan - pas voorafgaand aan de beëindiging van de gevangenisstraf of v.i.-periode of de tenuitvoerlegging van deze maatregel daadwerkelijk moet plaatsvinden. Ook worden eerst op dat moment de aan de GVM te verbinden voorwaarden en de duur van de maatregel door de rechter vastgesteld. De rechter kan de GVM gelasten indien sprake is van (a) een recidiverisico van zware geweldsdelicten of zedendelicten of (b) een noodzaak om ernstig belastend gedrag jegens slachtoffers of getuigen te voorkomen (art. 6:6:23b lid 1 Wetboek van Strafvordering $(\mathrm{Sv})$ ). Hoewel de maatregel minimaal twee en maximaal vijf jaar kan duren, kan deze telkens - en daarmee oneindig - op vordering van het Openbaar Ministerie worden verlengd. Gedurende de tenuitvoerlegging van de GVM vindt door middel van toezicht vrijheidsbeperking plaats of worden aan de veroordeelde voorwaarden opgelegd met als doel zijn gedrag positief te beïnvloeden.

Daarnaast is de proeftijd van de aan de v.i. verbonden bijzondere voorwaarden gelijkgetrokken met die van de algemene voorwaarden. De proeftijd is thans gelijk aan de periode waarover v.i. wordt verleend, maar bedraagt ten minste een jaar (art. 6:1:18 lid $2 \mathrm{~Sv}$ ). Verder is het mogelijk gemaakt om de proeftijd van de v.i. met maximaal twee jaar te verlengen. Behoudens het in de memorie van toelichting genoemde criterium van het gedrag van de veroordeelde, ${ }^{10}$ zijn aan deze verlengingsmogelijkheid geen nadere eisen gesteld. Voor delinquenten die zijn veroordeeld tot een ernstig gewelds- of zedendelict als bedoeld in artikel $38 \mathrm{z}$ lid 1 onder $\mathrm{b}$ en $\mathrm{c}$ Sr, is een bijzondere regeling ingevoerd. Bij die groep delinquenten kan de rechter de proeftijd telkens met twee jaar - en daarmee oneindig - verlengen indien sprake is van een ernstig vermoeden dat de veroordeelde met een in ernst vergelijkbaar delict recidiveert, of indien de noodzaak tot het voorkomen van ernstig belastend gedrag jegens slachtoffers of getuigen daartoe aanleiding geeft. Zodoende kan in de gevallen waarin de rechter géén GVM heeft opgelegd, een in duur vergelijkbaar toezichtkader worden gecreëerd via de proeftijd van de v.i.

\section{De v.i.-regeling en de nieuwe bijzondere voorwaarden}

Met ingang van 1 januari 2020 is de wettelijke regeling van de v.i., de laatste fase van de tenuitvoerlegging van de gevangenisstraf, geheel overgeheveld naar het nieuwe Boek 6 van het Wetboek van Strafvordering. ${ }^{11}$ Als algemene opdracht geldt 
dat bij de tenuitvoerlegging rekening moet worden gehouden met alle relevante belangen, waaronder de veiligheid van de samenleving, de belangen van slachtoffers en nabestaanden, en de resocialisatie van de veroordeelde (art. 6:1:3 Sv).$^{12} \mathrm{Het}$ v.i.-stelsel, zoals we dat sinds 2008 kennen, is met deze grotendeels wetstechnische wijzigingen nagenoeg onveranderd gebleven. Zo is de opsomming van de algemene en bijzondere voorwaarden betreffende het gedrag van de veroordeelde (art. 15a Sr (oud)) onverkort in het nieuwe artikel 6:2:11 Sv opgenomen. De v.i. is primair bedoeld om de veiligheid van de samenleving te vergroten. Door middel van het gedurende een proeftijd onderwerpen van de veroordeelde aan toezicht wordt beoogd een bijdrage te leveren aan de bescherming van de maatschappij en het voorkomen van recidive. ${ }^{13}$ De bijzondere, op de persoon toegesneden voorwaarden zijn daarbij een instrument om het gedrag van de veroordeelde te beïnvloeden en een geleidelijke en gecontroleerde terugkeer in de samenleving te bevorderen. Volgens de wetsgeschiedenis verhouden de 'v.i.-voorwaarden' zich tot de gevangenisstraf, in de zin dat de bijzondere voorwaarden zo veel mogelijk moeten aansluiten bij het voorgaande detentie(faserings)traject en de in dat kader gestarte activiteiten en interventies. ${ }^{14}$ Indien de voorwaarden tijdens de periode van toezicht niet of onvoldoende worden nageleefd, kan de v.i. worden herroepen (art. 6:2:13 Sv). De dreiging van de tenuitvoerlegging van het resterende gedeelte van de gevangenisstraf vormt hiermee een belangrijk middel om gedragsverandering teweeg te brengen.

Met de inwerkingtreding van de Wet straffen en beschermen wordt de opsomming van de bijzondere voorwaarden in artikel 6:2:11 lid 3 Sv aanzienlijk uitgebreid. Een uitvoerige toelichting over de rechtvaardiging en noodzaak van deze wijziging is echter niet gegeven. Er is volstaan met een verwijzing naar de voorwaarden die in het kader van de GVM kunnen worden gesteld. Volgens de beknopte uitleg moet de legitimatie voor de uitbreiding worden gezocht in de aansluiting met de lijst van voorwaarden zoals die in de regeling van de GVM is neergelegd. ${ }^{15}$ Zodoende kan een naadloze overgang tussen de v.i. en de GVM worden bereikt en kunnen slachtofferbelangen worden gewaarborgd. De voorwaarden betreffen een verbod zich op of in de directe omgeving van een bepaalde locatie te vestigen (woonverbod), een verbod vrijwilligerswerk van een bepaalde aard te verrichten, een beperking van het recht om Nederland te verlaten, de plicht te verhuizen uit een bepaald gebied, en het geheel of gedeeltelijk vergoeden van de door het strafbare feit veroorzaakte schade. Het woonverbod en de verhuisplicht zijn een verbijzondering van het al bestaande locatieverbod. In de situatie dat de veroordeelde zich na zijn vrijlating in de nabije woonomgeving van het slachtoffer wil vestigen, kan door middel van een

12 Kamerstukken II 2014/15, 34086, nr. 3, p. 33. Hoe deze belangen zich tot elkaar verhouden en hoe de afweging tussen deze belangen in een individueel geval moet plaatsvinden, is niet duidelijk. S. Meijer, 'De opmars en evolutie van het resocialisatiebegrip. De betekenis en ontwikkeling van resocialisatiebegrip in Europese en Nederlandse rechtspraak', DD 2015, 65.

13 Kamerstukken II 2005/06, 30513, p. 1, 4-5; Kamerstukken II 2018/19, 35122, nr. 3, p. 22; zie verder Uit Beijerse e.a. 2018, p. 27-29.

14 Kamerstukken II 2005/06, 30513, nr. 3, p. 10.

15 Zie het huidige art. 6:6:23b lid 2 Sv, voorheen art. 38ab lid 2 Sr (oud); Kamerstukken II 2018/19, 35122, nr. 7, p. 14. 
woonverbod of een verhuisplicht een ongewenste confrontatie tussen dader en slachtoffer worden voorkomen. ${ }^{16}$ Anders dan bij de laatste wijziging van de lijst van bijzondere voorwaarden uit 2012, betreft de nu aan de orde zijnde aanvulling niet slechts een wettelijke verankering van een al bestaande praktijk. ${ }^{17}$ Het gaat hier om nieuwe voorwaarden die vergaande beperkingen kunnen opleveren in de bewegingsvrijheid van de veroordeelde. Het brede samenstel van voorwaarden biedt mogelijkheden om bij de terugkeer van de veroordeelde in de maatschappij door middel van toezicht en controle nog steviger in te zetten op de bescherming van de samenleving en die van het slachtoffer in het bijzonder.

\section{Implicaties van de uitgebreide lijst van bijzondere voorwaarden}

De in paragraaf 2 uitgelichte onderdelen van de Wet langdurig toezicht kunnen worden verklaard in het licht van de wens van de wetgever om door middel van een persoonsgerichte aanpak toezicht te kunnen uitoefenen en aanwezige risico's in te perken. De gewijzigde invulling van de v.i.-periode, door de bijzondere voorwaarden in lijn te brengen met de voorwaarden van de GVM, heeft een soortgelijke strekking. Het past binnen de voortdurende behoefte van de wetgever om de maatschappij, en slachtoffers in het bijzonder, beter te beveiligen en te beschermen.

Over de wijze waarop dat moet gebeuren, zijn de meningen niet onverdeeld. De invoering van de GVM en de (oneindige) verlenging van de proeftijd van de v.i., evenals het feit dat deze toezichtkaders naast elkaar bestaan, hebben op de nodige kritiek kunnen rekenen. Met name over de toegevoegde waarde van de GVM in het licht van al bestaande vrijheidsbeperkende sancties en de proportionele verhouding tussen de duur van het toezicht en de ernst van het feit, in combinatie met de door de rechter vastgestelde schuld van de veroordeelde, zijn bezwaren geuit. ${ }^{18} \mathrm{Nu}$ de bijzondere voorwaarden in het kader van de v.i. worden aangevuld met de voorwaarden van de GVM, wordt in feite voortgebouwd op eerder bekritiseerde wetgeving. De wijziging tot uitbreiding van de bijzondere voorwaarden roept vragen op ten aanzien van het eigen karakter van de v.i., de rechtsbescherming van de veroordeelde gedurende de fase van voorwaardelijke invrijheidstelling en de (nieuwe) verhouding tussen de v.i. en de GVM. Deze thema's bespreek ik hierna in respectievelijke volgorde.

\subsection{Het eigen karakter van de v.i.}

Van oudsher wordt mede door middel van het stellen van bijzondere voorwaarden invulling gegeven aan het eigen karakter van de v.i. De Wet straffen en beschermen, waaronder de uitbreiding van de bijzondere voorwaarden, tornt echter aan dit typerende karakter. De v.i. is primair bedoeld om de veiligheid van de samenleving te

Kamerstukken II 2018/19, 35122, nr. 6, p. 67; Kamerstukken II 2018/19, 35122, nr. 7, p. 14.

Stb. 2011, 545.

Zie bijv. D. Broux, 'De (on)veiligheid van de zelfstandige gedragsbeïnvloedende en vrijheidsbeperkende maatregel', Strafblad 2017, 3, p. 248-255; B.W.A. Jue-Volker, 'Vrijheidsbeperking als strafrechtelijke sanctie', Sancties 2018, 64, p. 339-352; S. Struijk, 'Vrijheidsbeperking na detentie: in hoeverre zet de rechter de achterdeur open?', Sancties 2018, 65, p. 353-364. 
vergroten door een bijdrage te leveren aan de voorbereiding op een terugkeer in de samenleving en het verminderen van recidive. Volgens de toelichting op de Wet straffen en beschermen wordt hieraan toegevoegd dat de periode van vi. recht moet doen aan het karakter van de vrijheidsstraf, waaronder vergelding en herstel van de rechtsorde. ${ }^{19}$ Dat doet denken aan de regeling van de voorwaardelijke veroordeling, waarbij de daaraan te verbinden voorwaarden meer in het teken staan van een vorm van bestraffing, maar dan als alternatief voor de vrijheidsstraf. Destijds is in dit verband zelfs expliciet opgemerkt dat bijzondere voorwaarden als vergoeding of herstel van de door het strafbare feit veroorzaakte schade 'goed [passen] bij de voorwaardelijke veroordeling, maar minder geschikt [zijn] als voorwaarden bij voorwaardelijke invrijheidstelling. ${ }^{20}$ Van deze zienswijze is in de nieuwe v.i.-regeling weinig terug te zien. Integendeel, de vergoeding van de door het strafbare feit veroorzaakte schade wordt - in het belang van slachtoffers en nabestaanden - juist toegevoegd aan de opsomming van bijzondere voorwaarden in het kader van de v.i. Deze voorwaarde moet binnen de regeling van de v.i. volgens mij in die zin worden begrepen dat de dreiging van de tenuitvoerlegging van het strafrestant een prikkel vormt om het te vergoeden schadebedrag te betalen. In zoverre kan deze voorwaarde een instrument zijn om het gedrag positief te beïnvloeden. Hoewel het vanzelfsprekend wenselijk is dat slachtoffers de geleden schade vergoed krijgen en zij daar ook recht op hebben, valt evenwel moeilijk in te zien hoe deze voorwaarde recht doet aan het karakter van de vrijheidsstraf, de veroordeelde voorbereidt op een terugkeer in de maatschappij dan wel de kans op recidive doet verminderen. Terwijl het vergoeden van schade teruggrijpt op het gepleegde delict, is het aan de veroordeelde om zich gedurende de v.i. te richten op een delictvrije toekomst. Het breder inzetten van de v.i.-periode levert zo onduidelijkheid op over hoe de uiteenlopende doelstellingen en belangen zich (in het concrete geval) tot elkaar verhouden.

Daarnaast kan zich een aantal praktische problemen voordoen. In verband met de veelal beperkte financiële draagkracht van gedetineerden is in de memorie van toelichting opgemerkt dat het niet kúnnen voldoen aan een betalingsverplichting niet in de weg staat aan het verlenen van externe vrijheden. ${ }^{21}$ Voor degenen die hiertoe wel in staat zijn, is het de vraag of de gemaximeerde v.i.-termijn van twee jaar voldoende gelegenheid biedt om het volledige (hoge) schadebedrag te vergoeden. De mogelijkheid om de proeftijd te verlengen lijkt in deze gevallen onzuiver, nu dat volgens de wetgever is gereserveerd voor situaties waarin het gedrag van de veroordeelde of het aanwezige recidiverisico daartoe aanleiding geeft. ${ }^{22}$

De nieuwe invulling van de v.i.-periode laat ook een ander evenwicht zien ten aanzien van langs welke weg de veiligheid van de samenleving moet worden vergroot. Een intensivering van de bijzondere voorwaarden kan tot gevolg hebben dat de ruimte voor de veroordeelde om succesvol te re-integreren wordt ingeperkt. Met de uitbreiding van de bijzondere voorwaarden is nadrukkelijk een grotere plaats inge-

19 Kamerstukken II 2018/19, 35122, nr. 3, p. 5; zie verder Schuyt 2019, p. 10.

20 Kamerstukken II 2009/10, 32319, nr. 3, p. 14.

21 Idem.

22 Kamerstukken II 2013/14, 33816, nr. 3, p. 4 en 25; zie ook Aanwijzing voorwaardelijke invrijheidstelling (2020A010) onder III.3.2. 
ruimd voor beveiliging en controle, terwijl de door de reclassering geboden hulp en steun meer naar de achtergrond raakt. Het gevaar bestaat dat de voorbereiding van de veroordeelde op een geleidelijke terugkeer in de samenleving, een van de doelstellingen van de v.i., te veel buitenspel komt te staan. Daarmee ontwikkelt de v.i. zich meer en meer tot een beveiligingsmaatregel. De eerste stap daartoe werd reeds gezet met de introductie van de verlengingsmogelijkheid van de proeftijd, waardoor de koppeling tussen de v.i.-periode en de proeftijd werd losgelaten.

Het toevoegen van ingrijpende voorwaarden aan de opsomming van bijzondere voorwaarden kan nog een andere onwenselijke consequentie tot gevolg hebben. Een van de uitgangspunten van de nieuwe v.i.-regeling is dat bij beslissingen over het toekennen van vrijheden niet alleen rekening wordt gehouden met risico-inschatting en de belangen van de samenleving en van slachtoffers, maar ook met het gedrag van de gedetineerde gedurende de gehele detentie. ${ }^{23}$ Dat laatste heeft als doel om calculerend gedrag tegen te gaan. Al eerder is de zorg geuit dat een maximale v.i.-periode van twee jaar calculerend gedrag in de hand kan werken, waarbij gedetineerden bewust afzien van hun voorwaardelijke invrijheidstelling en een langere detentieperiode voor lief nemen om justitieel toezicht na invrijheidstelling te omzeilen. ${ }^{24}$ Met het 'verzwaren' van de v.i. door middel van een verhuisplicht, een woonverbod, een reisverbod en een verbod om vrijwilligerswerk van bepaalde aard te verrichten, is deze zorg beslist reëel en vooral onwenselijk. Dergelijke voorwaarden zijn in het bijzonder relevant voor zware gewelds- en zedendelinquenten. Juist bij deze categorie veroordeelden is het, met het oog op hun re-integratie en het verminderen van het risico op recidive, wenselijk dat zij van de v.i. gebruikmaken, zeker indien de strafrechter de oplegging van een GVM achterwege heeft gelaten.

\subsection{Rechtsbescherming van de veroordeelde}

De geïntensiveerde invulling van de v.i.-periode roept eveneens vragen op ten aanzien van rechtswaarborgen, ter voorkoming van willekeurige en disproportionele toepassing van de bijzondere voorwaarden.

Kenmerkend voor de fase van de v.i. is dat wettelijk vastgelegde criteria voor het opleggen van bijzondere voorwaarden ontbreken. Dat dient bij uitstek een flexibele en persoonsgerichte aanpak, een van de uitgangspunten van het nieuw ingevoerde systeem van detentiefasering. ${ }^{25}$ De aanzienlijke uitbreiding van de mogelijke bijzondere voorwaarden komt echter de inzichtelijkheid en de voorzienbaarheid van de concrete tenuitvoerlegging van de v.i.-periode niet ten goede. ${ }^{26}$ Het gevolg is immers dat grote verschillen kunnen ontstaan, niet alleen ten aanzien van de (verlengde) duur van de v.i., maar ook tussen het aantal en de intensiteit van de op te leggen bijzondere voorwaarden. In het bijzonder kunnen veroordeelden die een delict hebben gepleegd met een aanwijsbaar slachtoffer zich geconfronteerd zien met zeer ingrijpende voorwaarden. Hierbij bestaat het risico dat de samenhang 
tussen het bewezen verklaarde feit, in combinatie met de vastgestelde schuld van de verdachte, en de wijze van tenuitvoerlegging (verder) vervaagt. Hoewel de 'GVM-voorwaarden' zogezegd delictgerelateerd zijn en zijn beperkt tot zware gewelds- en zedendelinquenten, kunnen diezelfde ingrijpende voorwaarden worden opgelegd aan iedere veroordeelde die voorwaardelijk in vrijheid wordt gesteld. Hier wringt het dat bij het stellen van bijzondere voorwaarden - door het Openbaar Ministerie - geen begrenzende elementen bestaan om de voorwaarden van kaders te voorzien en schendingen van grondrechten te voorkomen. Bij de GVM is dat anders. Hoewel ruim geformuleerd, is aan de tenuitvoerlegging van de GVM de eis verbonden dat sprake is van een ernstig recidiverisico en een noodzaak om ernstig belastend gedrag jegens slachtoffers of getuigen te voorkomen (art. 6:6:23b lid 1 Sv). ${ }^{27}$ Dergelijke normeringen zijn ten aanzien van het stellen van bijzondere voorwaarden tijdens de v.i. niet in de wet opgenomen. Dat de op te leggen bijzondere voorwaarden in het teken dienen te staan van het al afgelegde detentietraject en de recidivedreiging die van de persoon van de betrokkene uitgaat, biedt in dit opzicht weinig houvast. ${ }^{28}$ Volgens de parlementaire geschiedenis van de GVM werd de grote mate waarin inbreuken kunnen worden gemaakt op de bewegingsvrijheid van de veroordeelde onder meer gelegitimeerd door het feit dat beslissingen tot oplegging en daadwerkelijke tenuitvoerlegging van de maatregel, alsook de concrete invulling en duur daarvan, zijn voorbehouden aan een onafhankelijke rechter. ${ }^{29} \mathrm{Na}$ de inwerkingtreding van de Wet straffen en beschermen zijn voor de v.i. vergelijkbare beslissingen toebedeeld aan het Openbaar Ministerie. ${ }^{30}$ Gelet op de aanzienlijke inbreuken die op grondrechten kunnen worden gemaakt, in combinatie met de afwezigheid van een onafhankelijke rechter, is het bedenkelijk dat geen rechterlijke bezwaar- en/of beroepsmogelijkheid openstaat indien de veroordeelde voorwaardelijk in vrijheid wordt gesteld. ${ }^{31}$ Alleen bij een eventuele verlenging van de proeftijd van de v.i. - dus eerst na maximaal twee jaar - beoordeelt de rechter, aan de hand van het gedrag van de veroordeelde, of een verlenging van de proeftijd, en de daaraan verbonden voorwaarden, noodzakelijk en proportioneel is.

\subsection{Verhouding tussen v.i. en GVM}

Tot slot is het de vraag hoe de v.i. en de GVM, als gevolg van de uitbreiding van de bijzondere 'v.i.-voorwaarden', zich tot elkaar verhouden. Deze twee juridische ka-

27 Ook ter vergelijking: om de proportionaliteitstoets te kunnen doorstaan moet bij het opleggen van voorwaarden in het kader van de vrijheidsbeperkende maatregel (art. 38v Sr) rekening worden gehouden met de woon- en werkomgeving van de veroordeelde; Kamerstukken II 2010/11, 32551, nr. 6, p. 2, 7, 18.

28 Vgl. Aanwijzing voorwaardelijke invrijheidstelling (2020A010). Op grond van art. 2:2 lid 1 Besluit USB dient de beslissing van het Openbaar Ministerie om bijzondere voorwaarden te stellen gemotiveerd te zijn, waarbij rekening is gehouden met de adviezen van de reclassering en de inrichtingsdirecteur (art. 2:1 Besluit USB). Deze motiveringsplicht biedt evenwel geen aanknopingspunten voor een bepaalde begrenzing van de bijzondere voorwaarden.

29 Kamerstukken II 2013/14, 33816, nr. 3, p. 50.

30 De beslissing omtrent het stellen van bijzondere voorwaarden is thans al gegeven aan het Openbaar Ministerie.

31 De veroordeelde kan bij de rechter wel een bezwaarschrift indienen tegen de beslissing om geen v.i. te verlenen en tegen de (gedeeltelijke) herroeping van de v.i.; Kamerstukken II 2018/19, 35122, nr. 3, p. 25. 
ders zijn in veel opzichten vergelijkbaar. De mogelijk op te leggen voorwaarden komen nagenoeg overeen en zowel de GVM als de proeftijd bij de v.i. kan voor zeden- en geweldsdelinquenten resulteren in levenslang toezicht. Voor de strafrechter kan dit reden zijn de GVM níet op te leggen, dan wel de vordering tot tenuitvoerlegging af te wijzen. Anderzijds is het voorstelbaar dat de GVM zijn praktisch (beperkte) nut zal kunnen bewijzen, maar dan slechts in de gevallen waarin op grond van aanwezige risico's géén v.i. is verleend en/of de veroordeelde - al calculerend - zijn v.i.-periode doelbewust in detentie uitzit. ${ }^{32}$ De twijfel over of überhaupt tot het verlenen van v.i. wordt overgegaan en, indien dat wel gebeurt, de onzekerheid over de duur en invulling van het toezicht kan aanleiding zijn om de GVM zekerheidshalve op te leggen. ${ }^{33}$ In dat geval blijft echter alsnog ongewis of de tenuitvoerlegging van de maatregel daadwerkelijk wordt gelast indien de veroordeelde al in vrijheid is gesteld onder 'GVM-voorwaarden'. Zo bekeken, is het denkbaar dat van de GVM, vanwege de verruimde toezichtmogelijkheden binnen het kader van de v.i., minder gebruik zal worden gemaakt. Het is aldus de vraag hoe vaak de door de wetgever gewenste naadloze overgang tussen de v.i. en de GVM in de praktijk daadwerkelijk zal voorkomen.

Al bij de totstandkoming van de GVM zijn, tot slot, kritische noten gekraakt over de toegevoegde waarde van deze beveiligingsmaatregel. ${ }^{34}$ De wetgever gaf te kennen dat de toen bestaande toezichthoudende kaders, waaronder de proeftijd van de v.i., voor zware delinquenten niet volstonden. ${ }^{35}$ Door de nieuwe uitbreiding van de 'v.i.-voorwaarden', en de al eerder ingevoerde mogelijkheid tot verlenging van de proeftijd, is de destijds gestelde waarde van de GVM nog meer op losse schroeven komen te staan.

\section{Tot besluit}

Onderdeel van de nieuwe v.i.-regeling is een aanzienlijke uitbreiding van de bijzondere voorwaarden die aan de voorwaardelijke invrijheidstelling van een veroordeelde kunnen worden gesteld. Hieraan ligt een vrij beperkte onderbouwing ten grondslag. Aanleiding vormt de (kennelijke) behoefte om de lijst van bijzondere voorwaarden in het kader van de v.i. naadloos te laten aansluiten bij de GVM. Dat heeft echter meer voeten in de aarde dan op het eerste oog lijkt. Een van de uitgangspunten van de Wet straffen en beschermen is dat recht wordt gedaan aan het karakter van de vrijheidsstraf, waaronder vergelding en herstel van de rechtsorde. Dat komt niet alleen tot uitdrukking in de gemaximeerde duur van de v.i., maar ook in de aangevulde lijst van bijzondere voorwaarden in het kader van de v.i. Dit leidt er echter toe dat het eigen karakter van de v.i. onder druk is komen te staan, of zelfs voor het merendeel is verdwenen, en dat het gemis aan juridische waarborgen en

32 De kans op een dergelijke calculerende opstelling van de verdachte was voor de reclassering in gerechtshof Amsterdam 19 februari 2021, ECLI:NL:GHAMS:2021:631 een argument om de GVM te adviseren, welk advies de rechter ook opvolgde.

33 Zie bijv. Rb. Noord-Nederland 18 februari 2020, ECLI:NL:RBNNE:2020:720.

34 Bijv. Broux 2017, p. 248-255.

35 Kamerstukken II 2013/14, 33816, nr. 3, p. 51. 
rechtsbescherming van de veroordeelde zwaarder wordt gevoeld naarmate de periode van v.i. intensievere vormen aanneemt. Verder heeft de wetswijziging tot gevolg dat met de v.i. en GVM, wat betreft de duur en concrete invulling, twee vergelijkbare juridische kaders naast elkaar bestaan, waardoor de GVM lijkt te zijn gereserveerd voor uitzonderingsgevallen. Het door de wetgever aangedragen argument om de 'v.i.-voorwaarden' in lijn te brengen met 'GVM-voorwaarden', wordt hiermee grotendeels ondergraven.

Het is daarom de vraag of had moeten worden overgegaan tot het uitbreiden van de bijzondere voorwaarden binnen het kader van de vi. Het voorgaande laat in ieder geval zien dat dit min of meer geruisloos toegevoegde onderdeel van de Wet straffen en beschermen stuit op principiële vragen over het stelsel van de v.i., waarover nadere gedachtevorming wenselijk was geweest en waarmee de rechtspraktijk, gezien de verslechterde positie van de veroordeelde, zorgvuldig zal moeten omgaan. In de zoektocht naar manieren waarop de samenleving en in het bijzonder slachtoffers beter beschermd kunnen worden, blijft het steeds van belang fundamentele rechten van de veroordeelde en het belang van een succesvolle re-integratie niet uit het oog te verliezen. 